Supplement of Biogeosciences, 12, 3061-3070, 2015

http://www.biogeosciences.net/12/3061/2015/

doi:10.5194/bg-12-3061-2015-supplement

(C) Author(s) 2015. CC Attribution 3.0 License.

(c) (i)

Supplement of

\title{
Lunar periodicity in the shell flux of planktonic foraminifera in the Gulf of Mexico
}

\section{Jonkers et al.}

Correspondence to: L. Jonkers (jonkersl@cardiff.ac.uk)

The copyright of individual parts of the supplement might differ from the CC-BY 3.0 licence. 


\section{Figure captions:}

S1 (page 3-13): periodograms of the size-fractionated fluxes of 11 species of planktonic Foraminifera in the Gulf of Mexico. See Fig. 2 for more details.

S2 (page 14-24): temporal expression of lunar periodicity in the shell flux of 11 species of planktonic Foraminifera in the Gulf of Mexico. See Fig. 3 for more details.

S3 (page 25-26): phasing of the lunar cycle in the shell fluxes of 11 species of planktonic Foraminifera in the Gulf of Mexico. Only size fractions that showed significant spectral power at the lunar frequency are shown. See Fig. 4 for more details. 
ऐัे

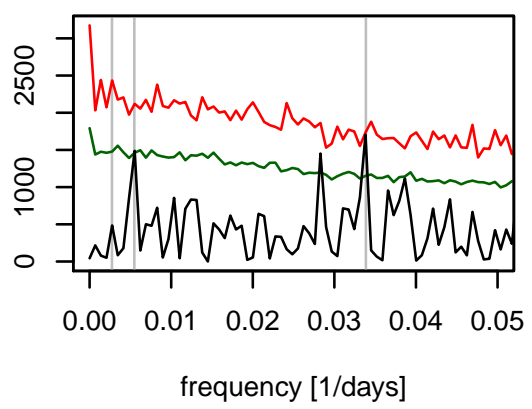

G_men300

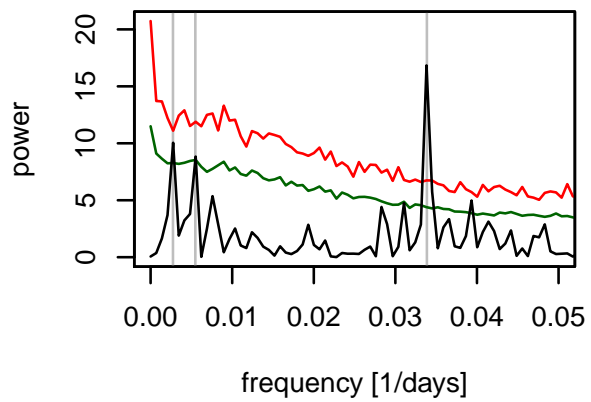

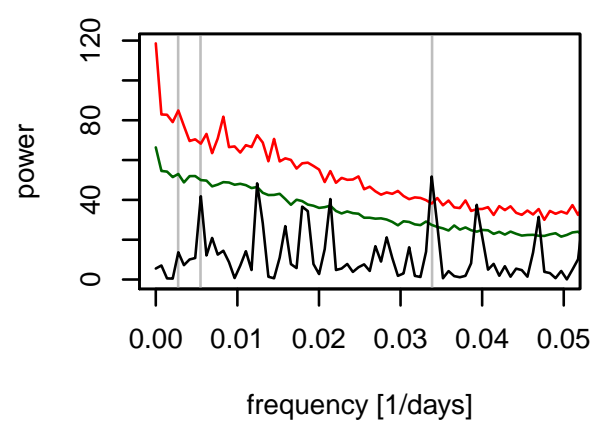

G_men212

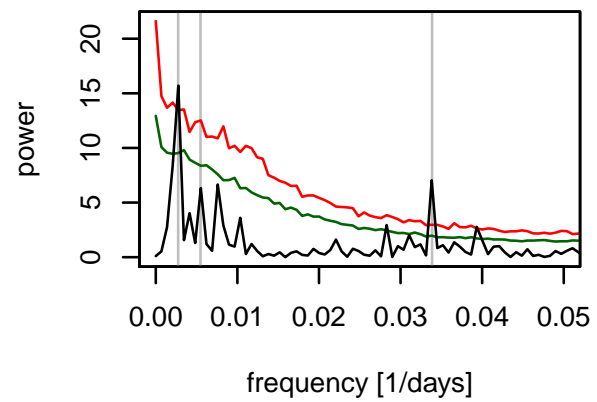

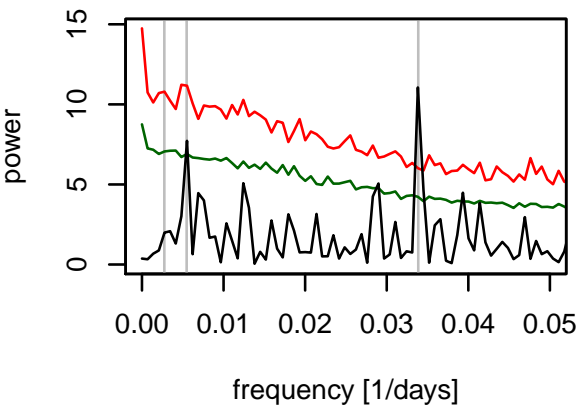

G_men150

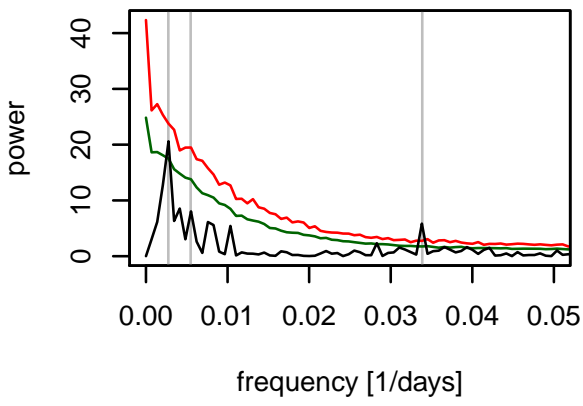


G_sip600

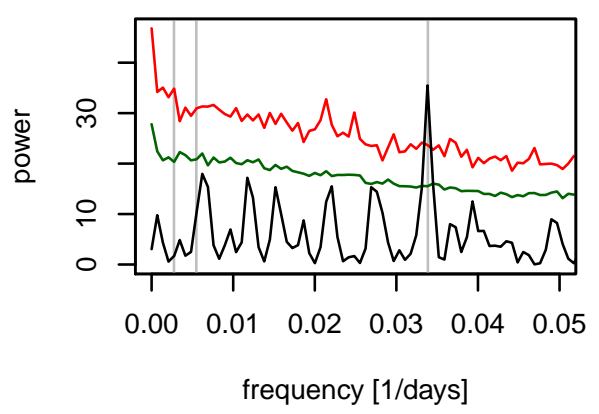

G_sip300

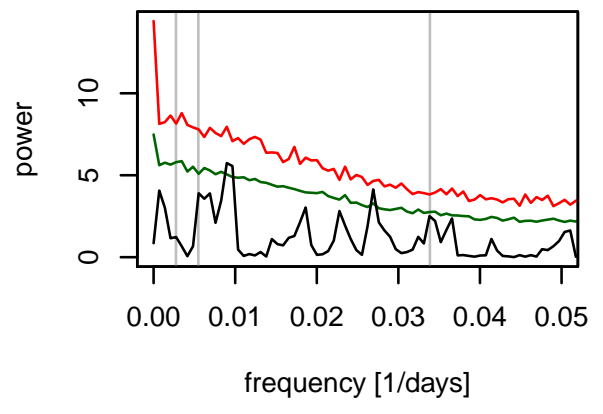

G_sip500

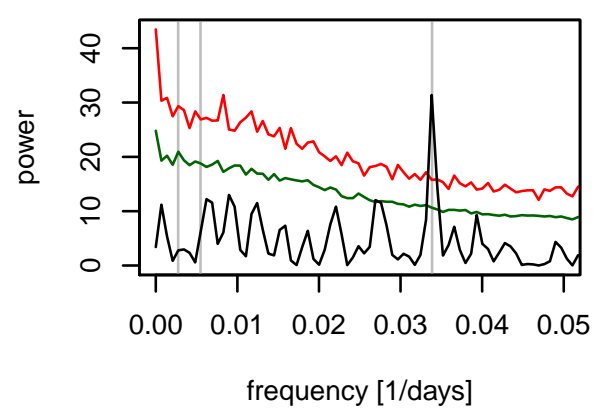

G_sip212

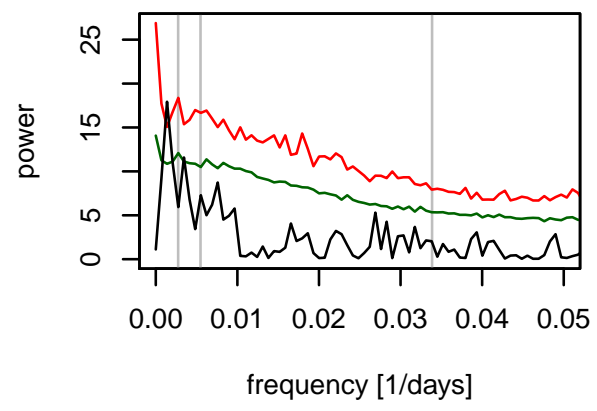

G_sip425

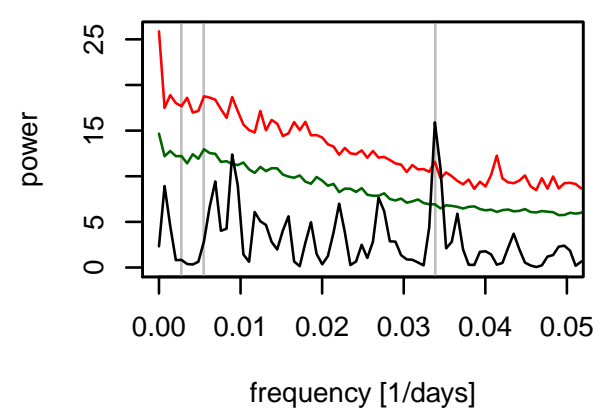

G_sip150

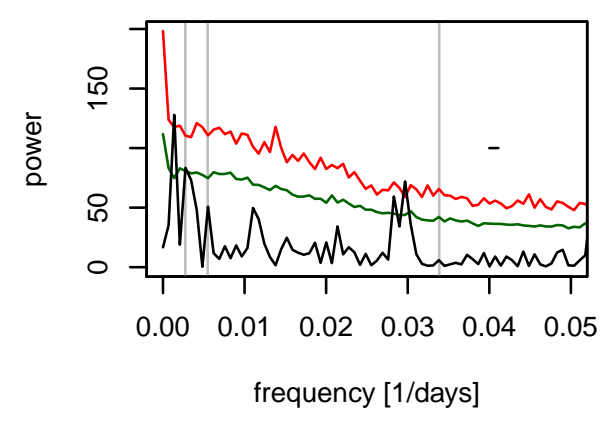


O_uni600

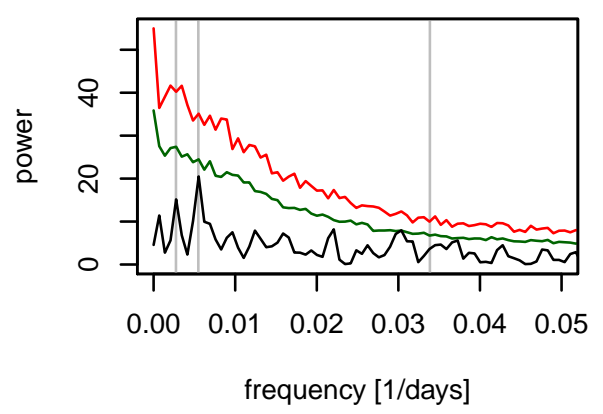

O_uni300

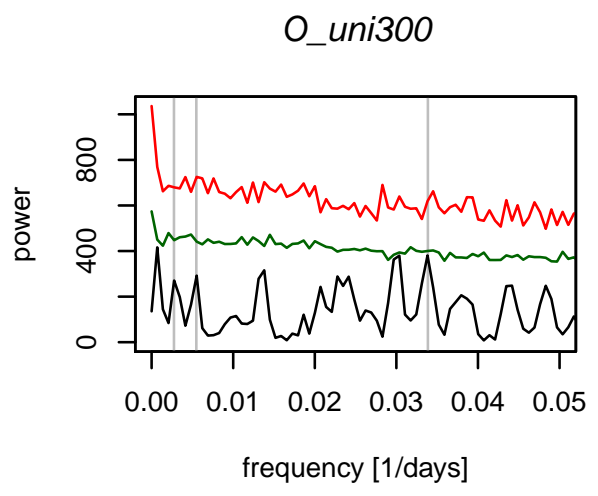

O_uni500

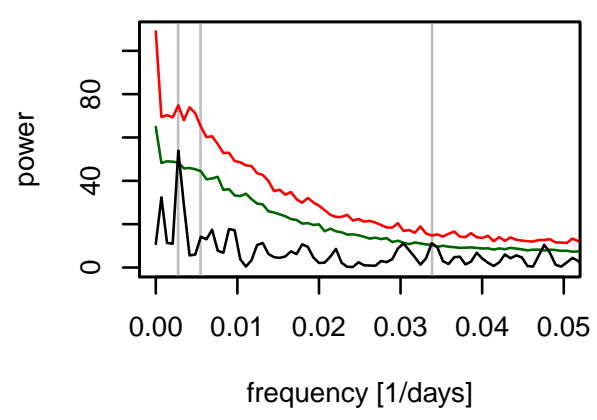

O_uni425

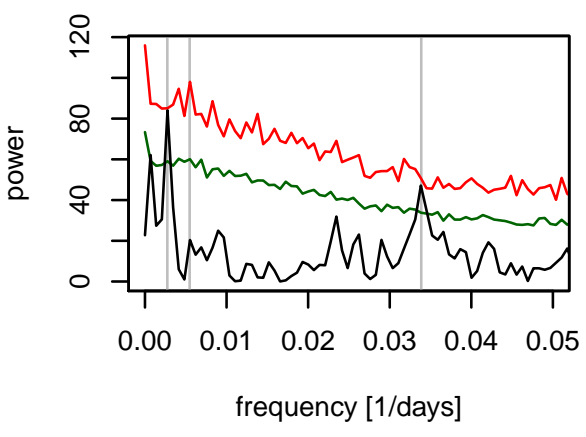


G_sac600

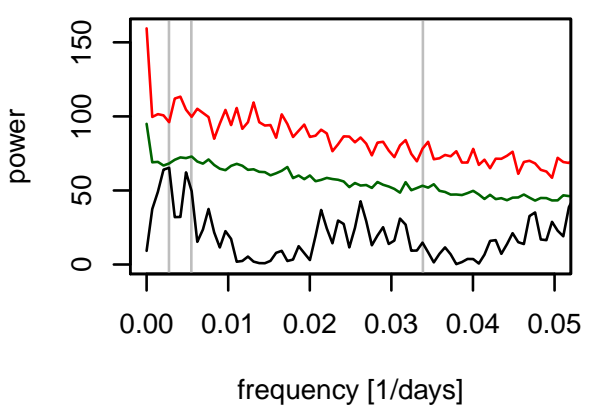

G_sac300

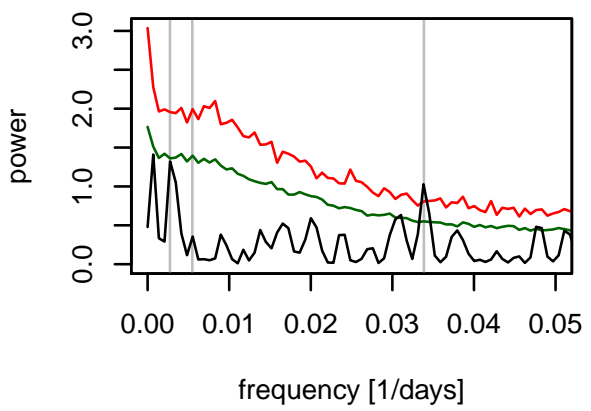

G_sac500

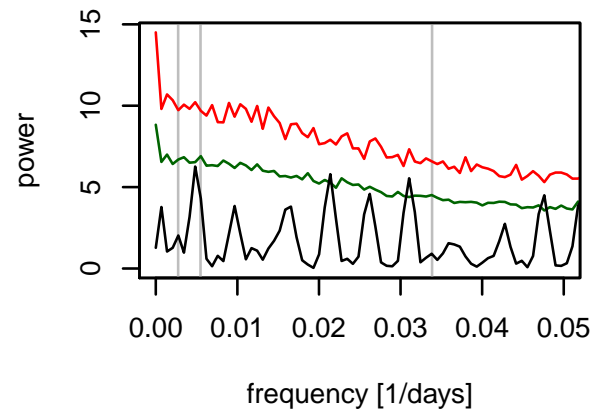

G_sac212

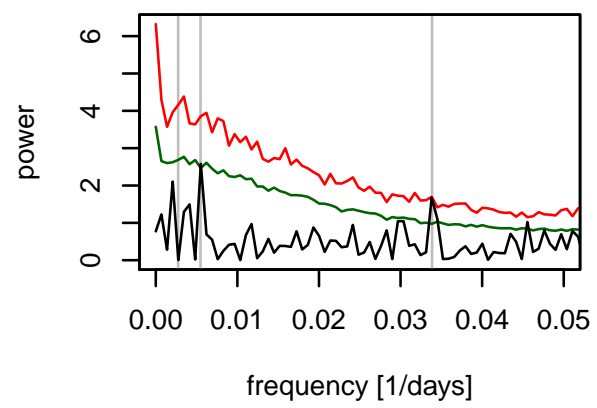

G_sac425

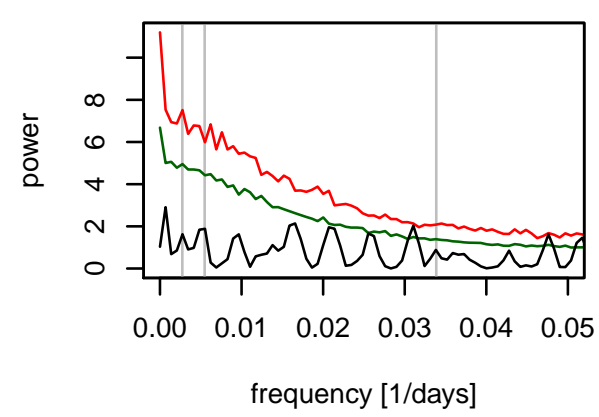

G_sac150

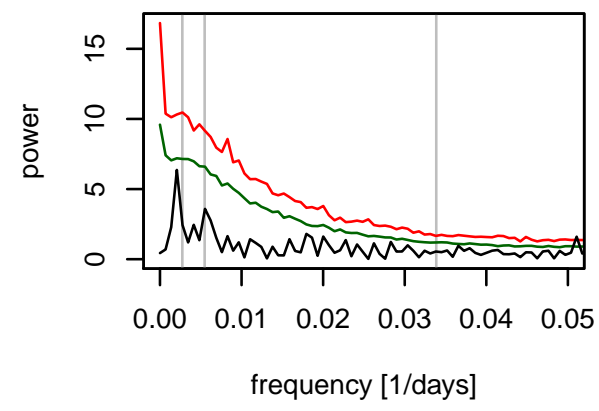


G_rubp500

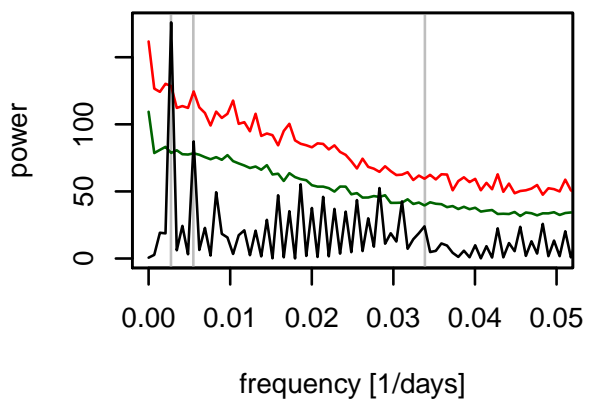

G_rubp212

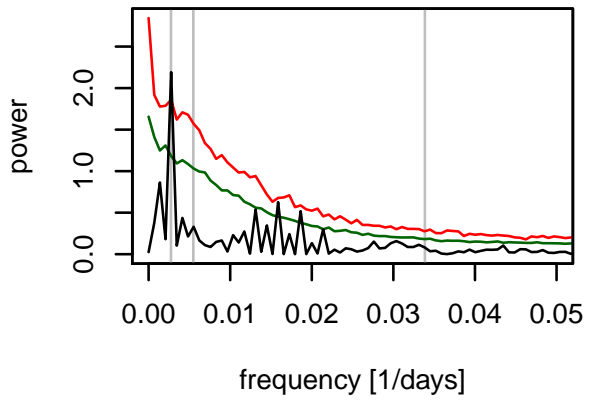

G_rubp425

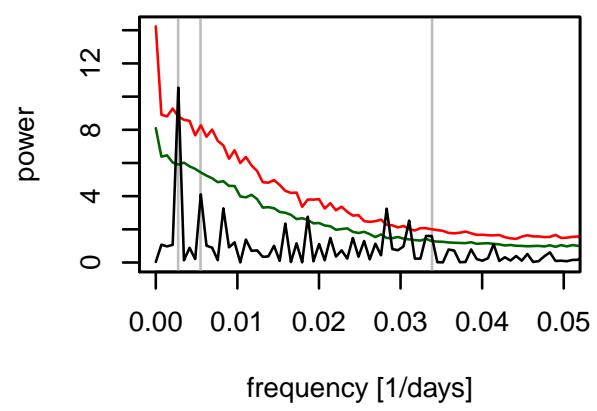

G_rubp150

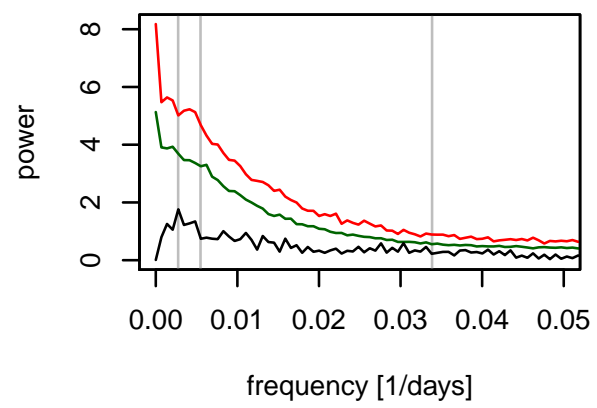

G_rubp300

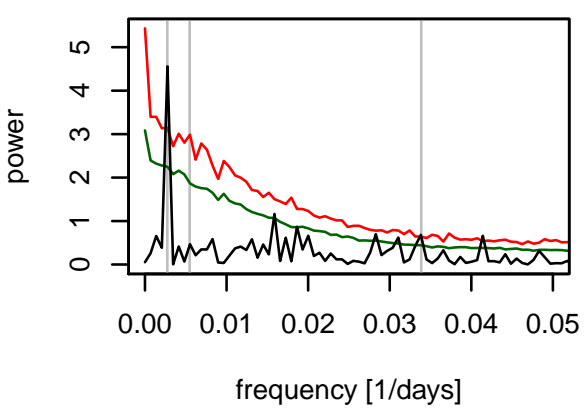

frequency [1/days] 
G_rubw425

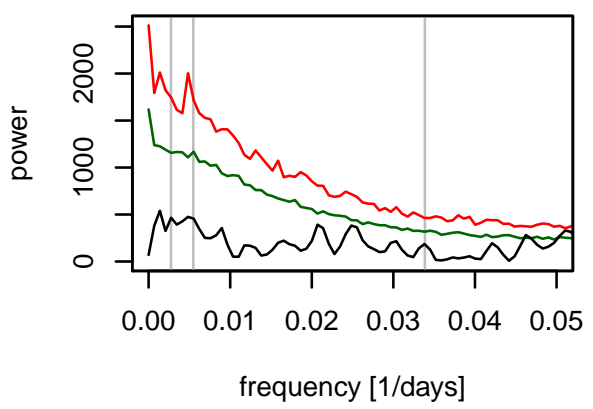

G_rubw150

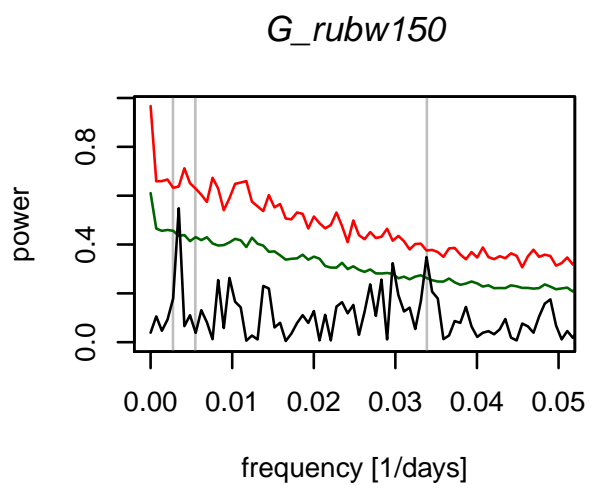

G_rubw300

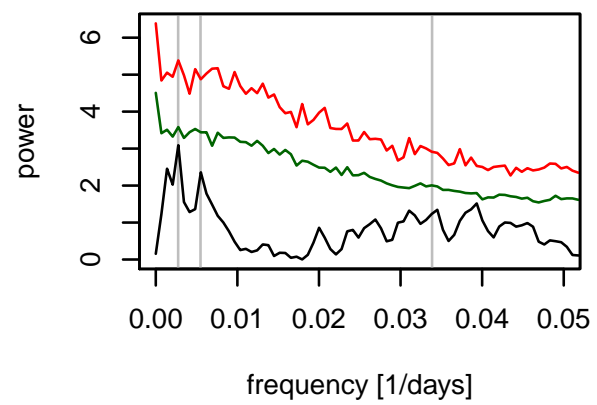


P_obl500

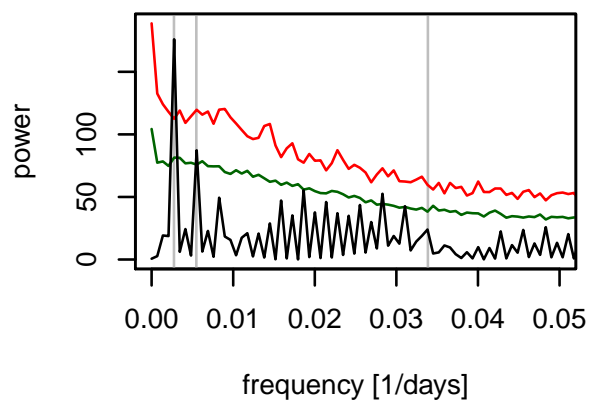

P_obl212

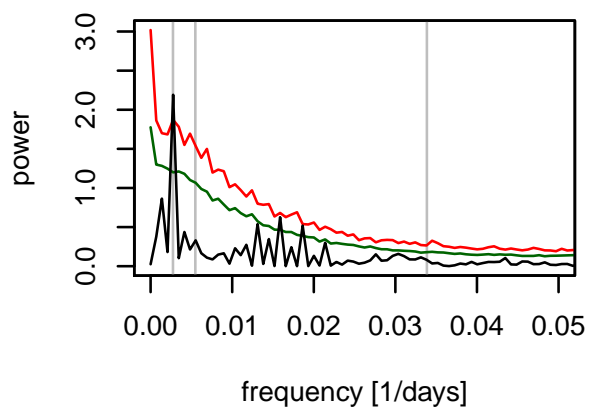

P_obl425

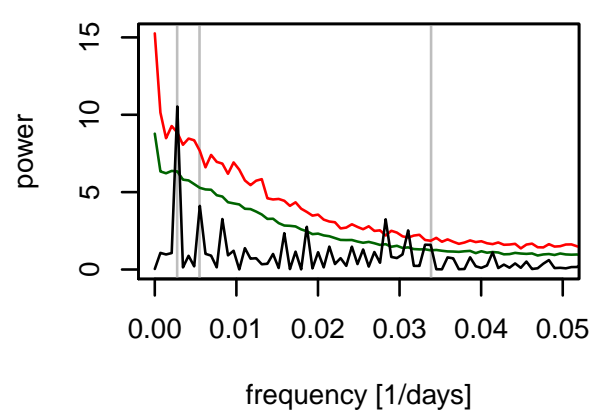

P_obl150

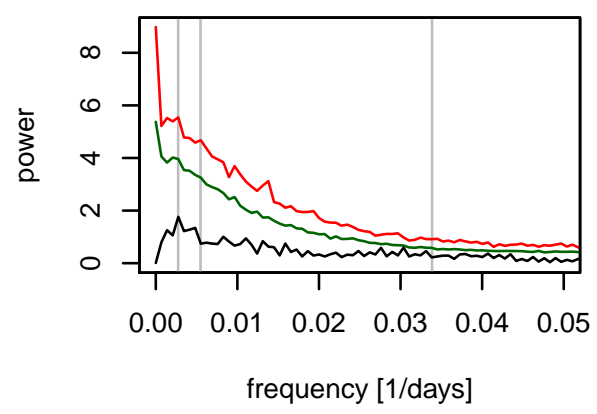

P_ob/300

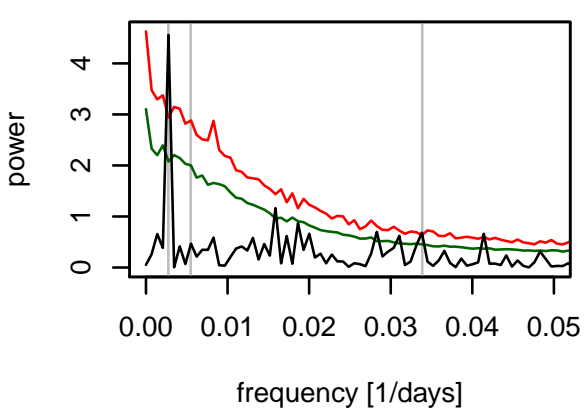

frequency [1/days] 
N_dut425

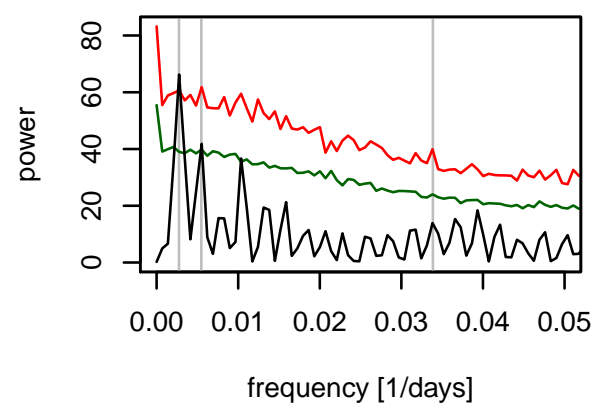

N_dut150

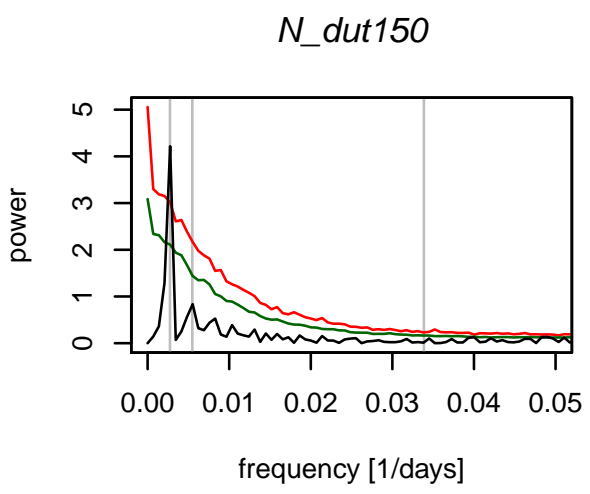

N_dut300

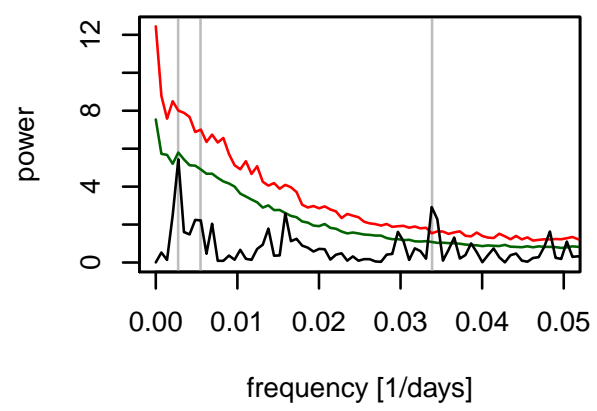

N_dut212

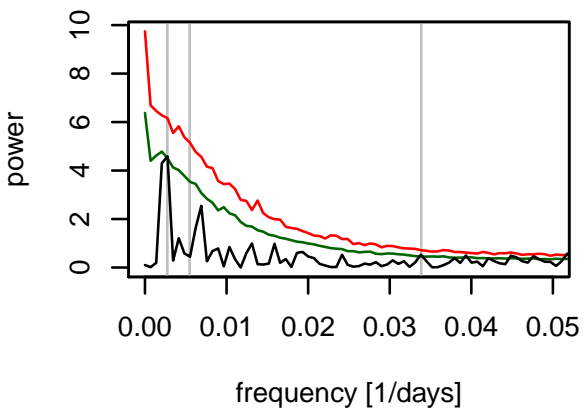


G_cal425

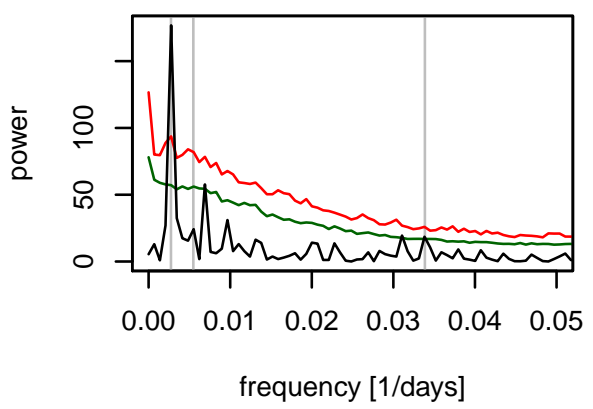

G_cal150

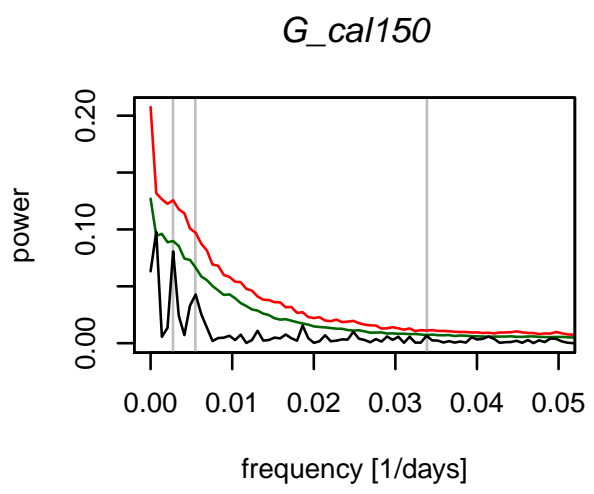

G_cal300

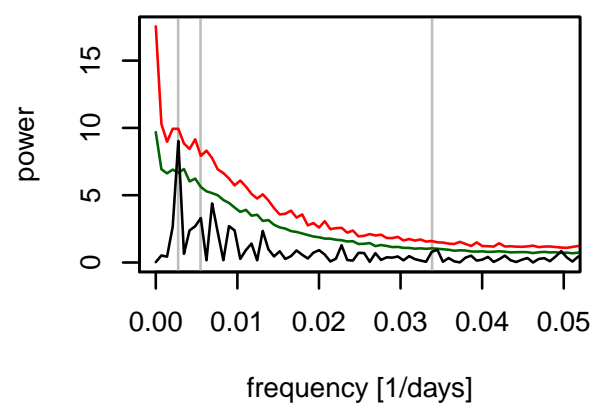

G_cal212

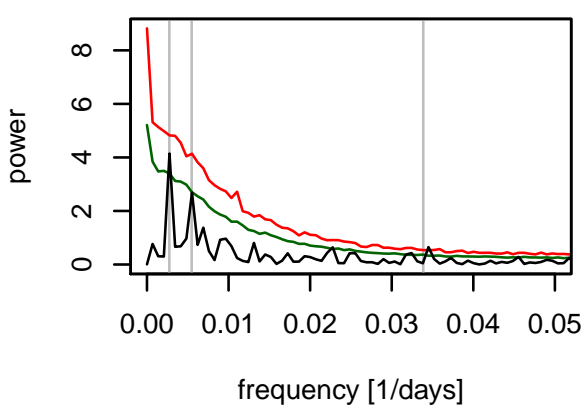


G_cra425

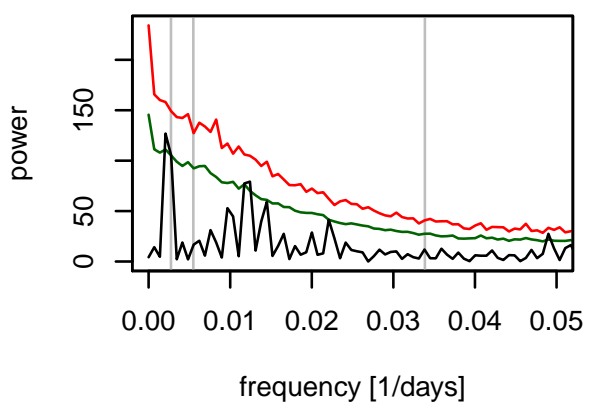

G_cra150

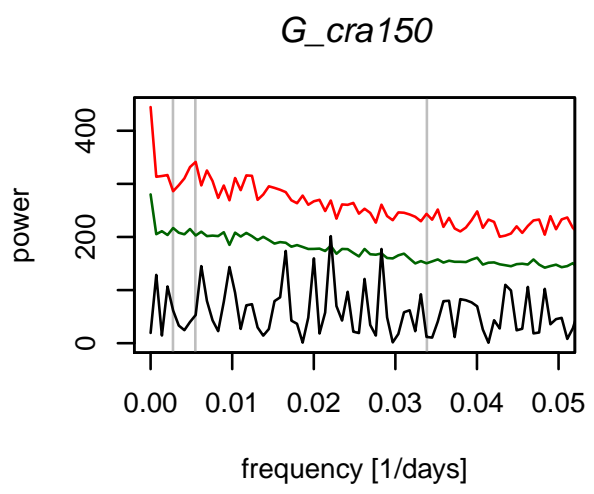

G_cra300

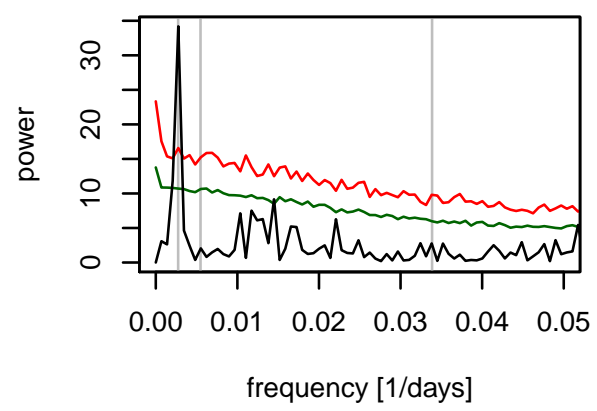

G_cra212

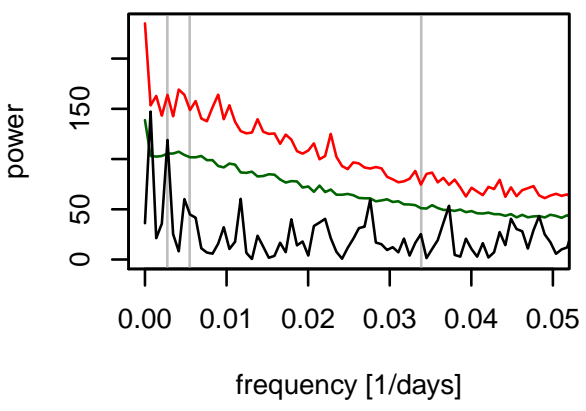



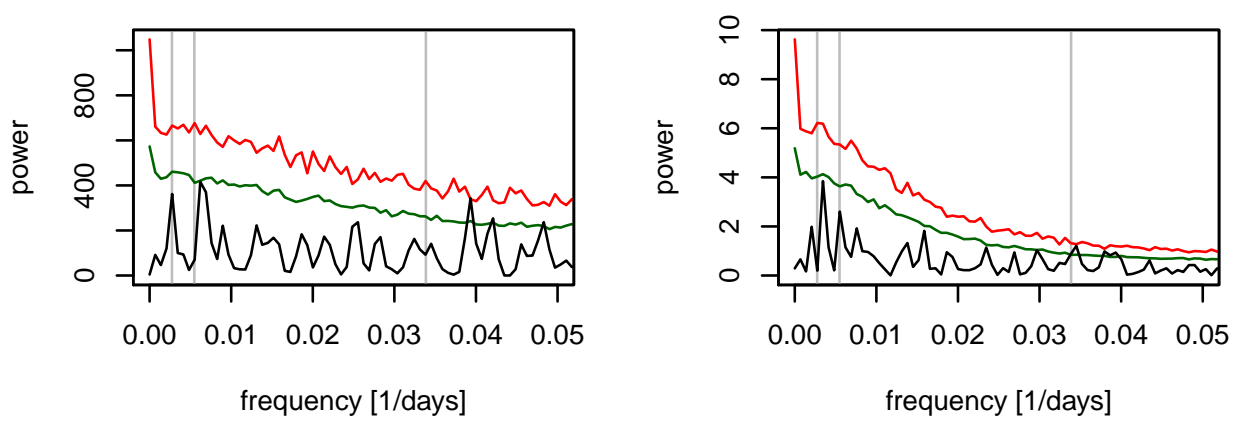


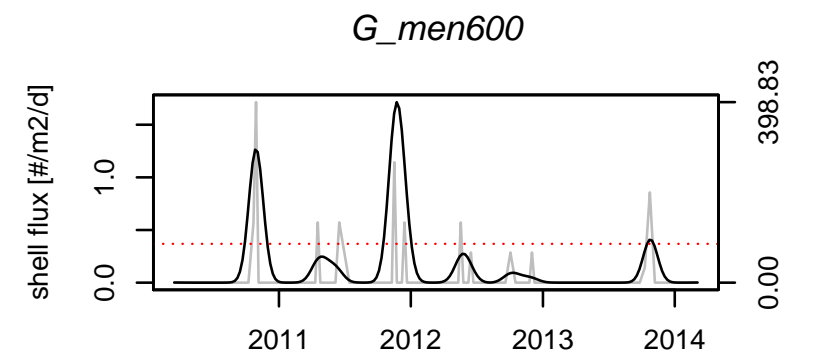

G_men425

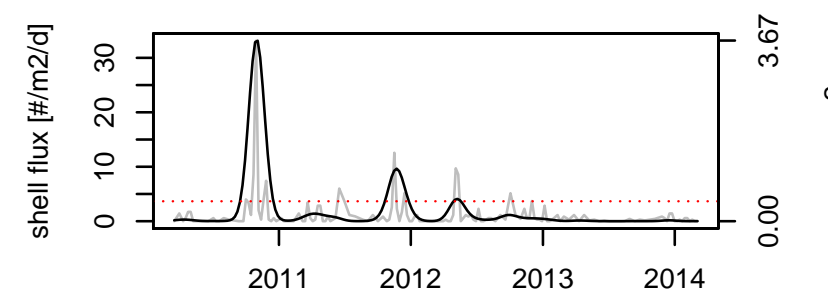

G_men212

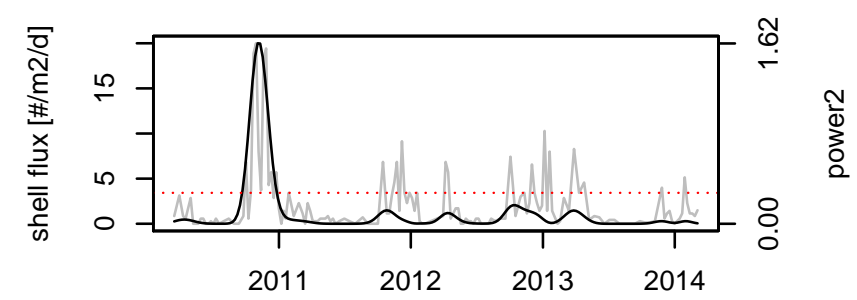

G_men500

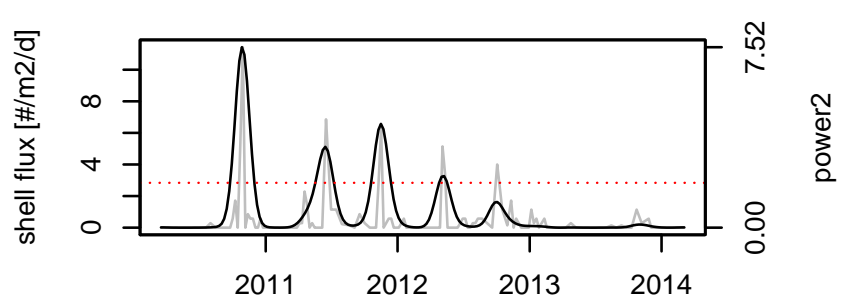

G_men300

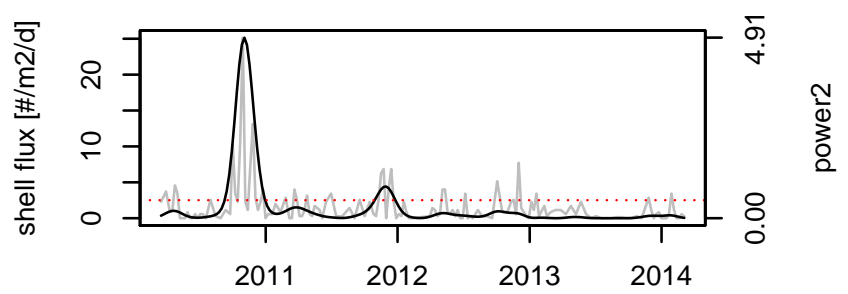

G_men150

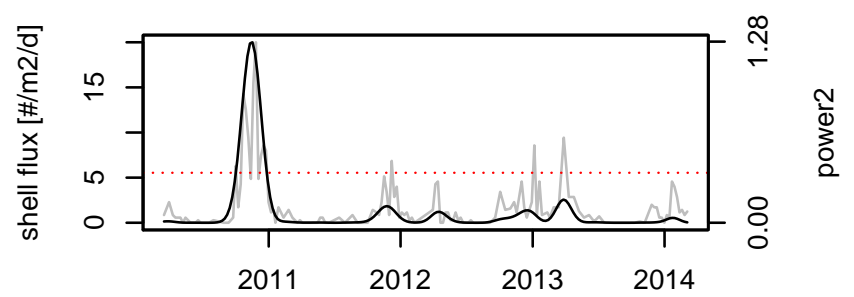




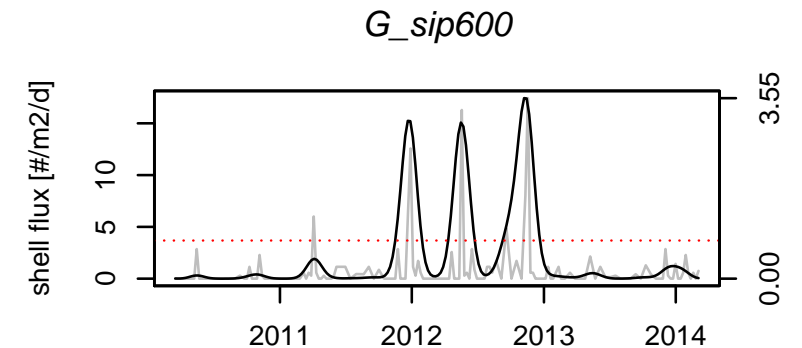

ํํำ

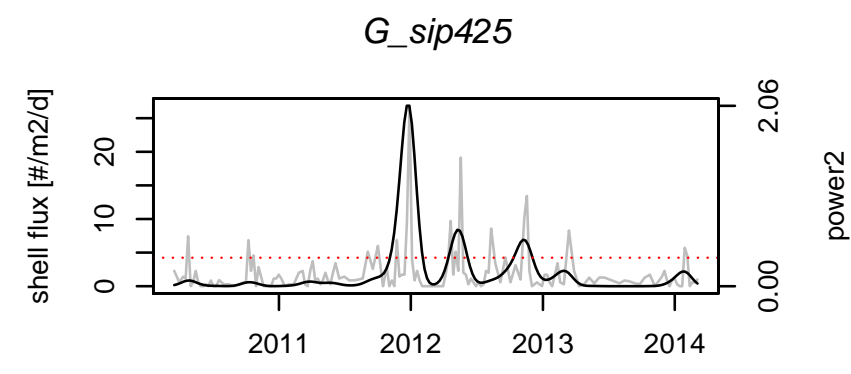

G_sip212

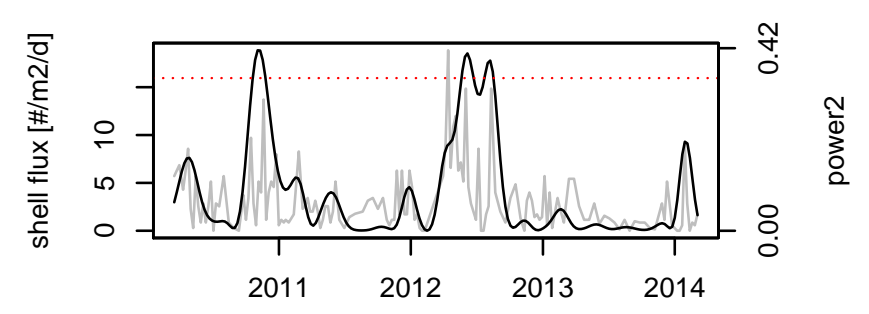

G_sip500

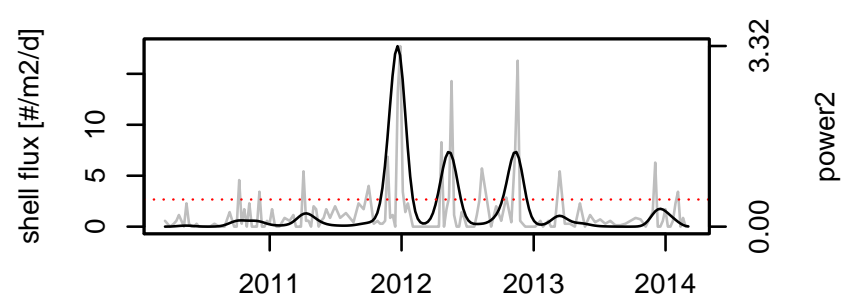

G_sip300

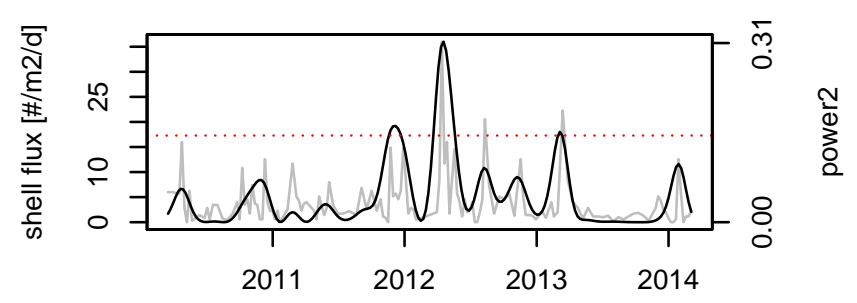

G_sip150

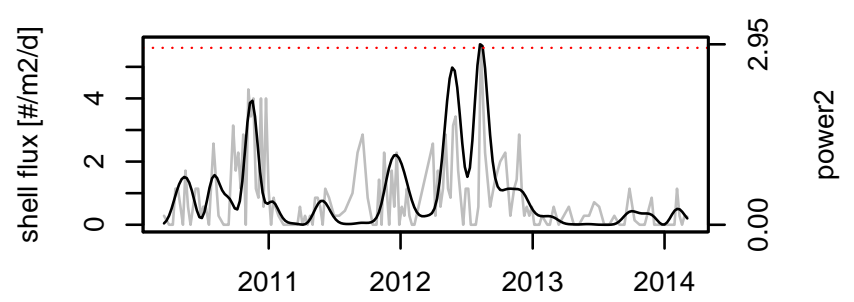


O_uni600

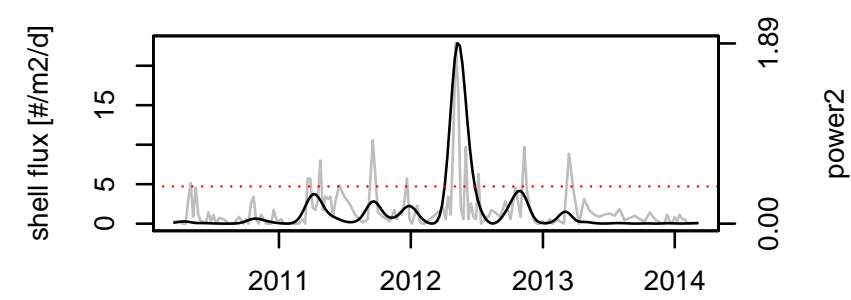

O_uni425

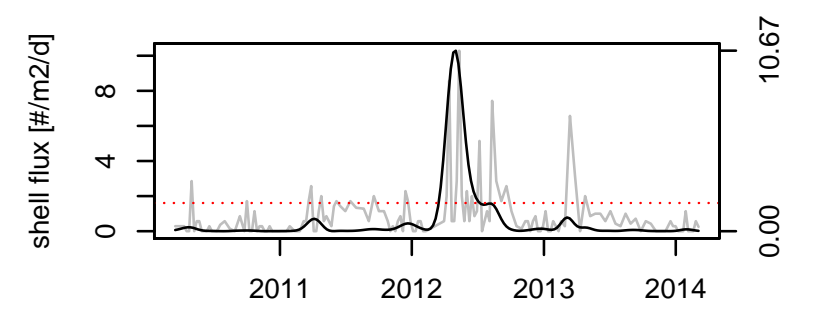

O_uni212

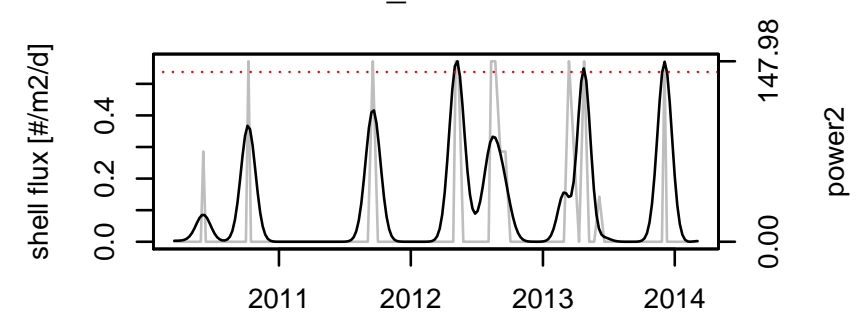

O_uni500

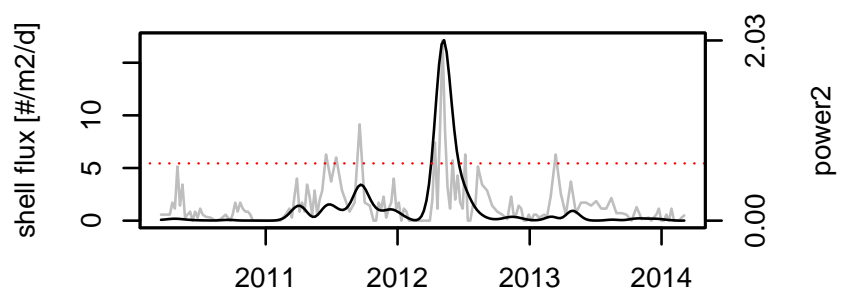

O_uni300

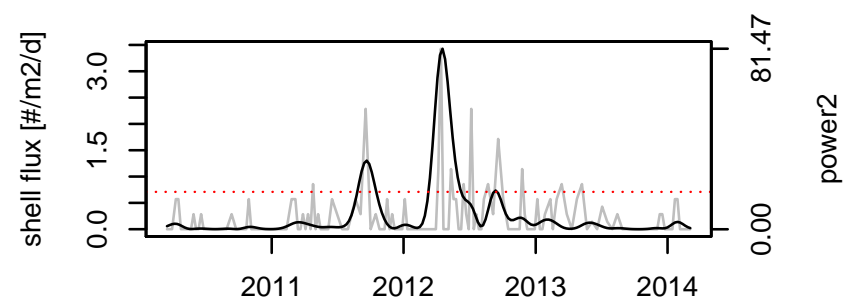

O_uni150

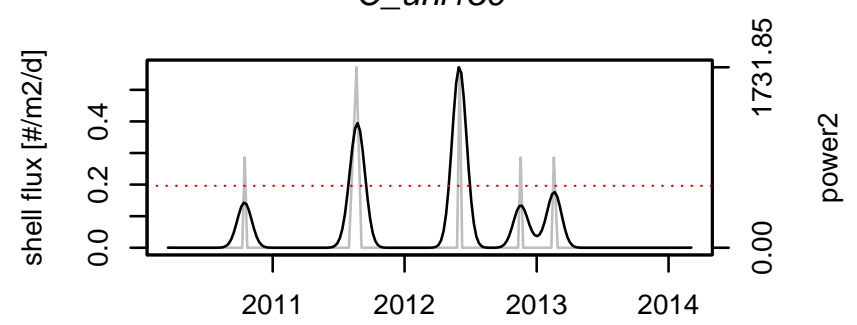



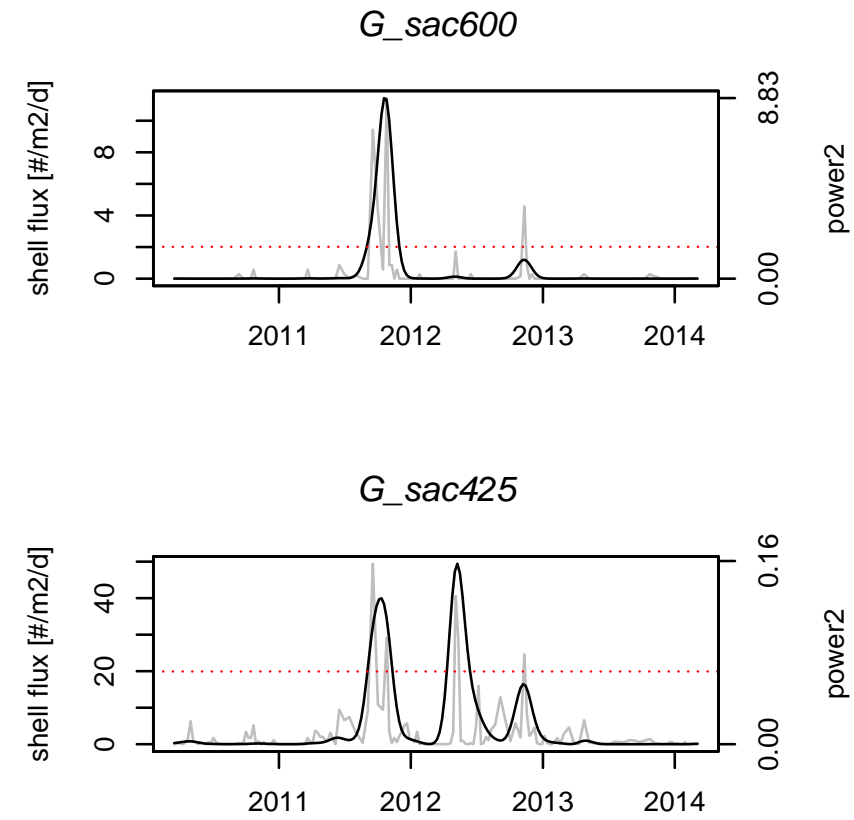

G_sac212

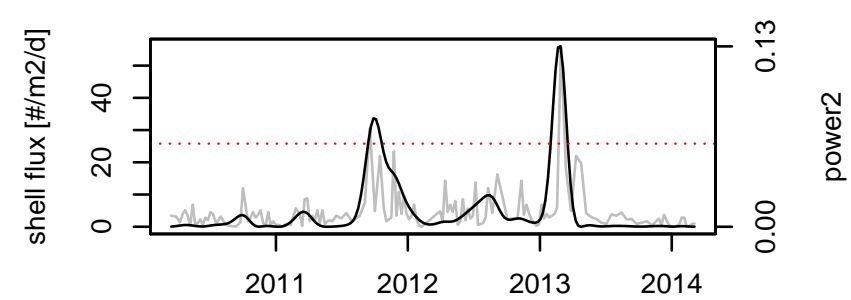

G_sac500

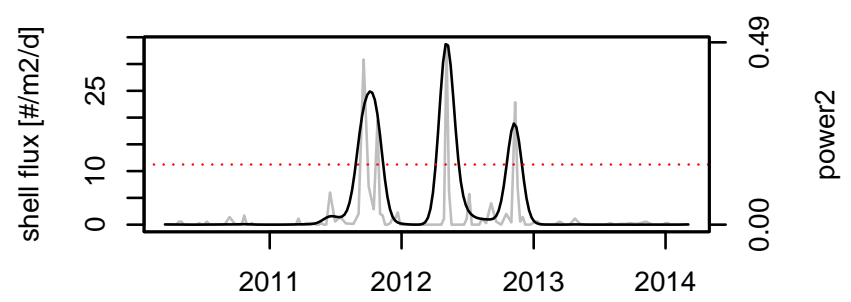

G_sac300

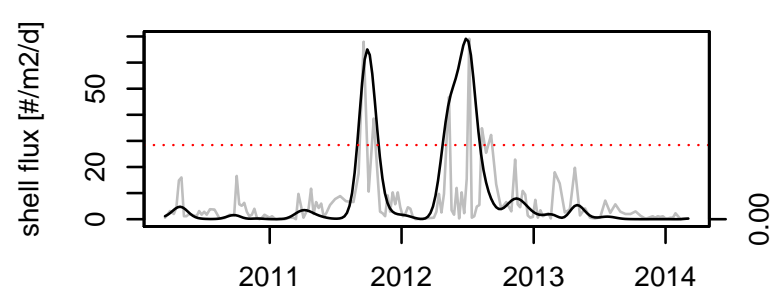

G_sac150

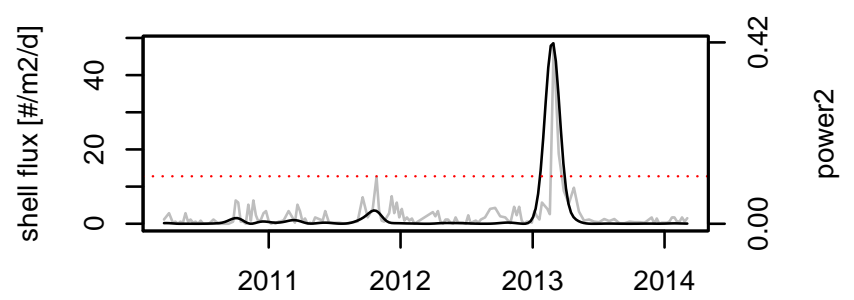


G_rubp500

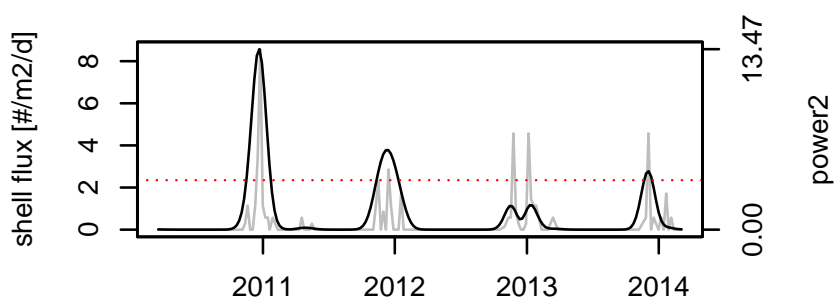

G_rubp300

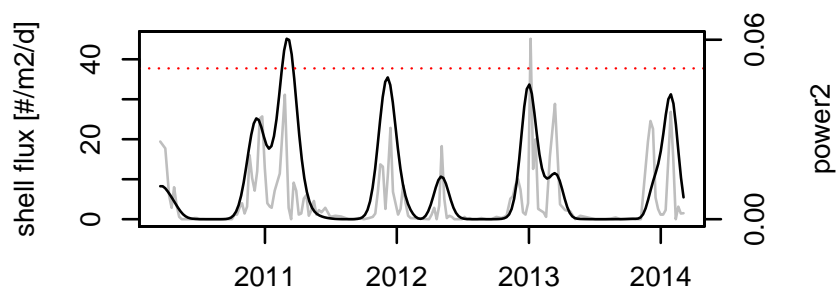

G_rubp150

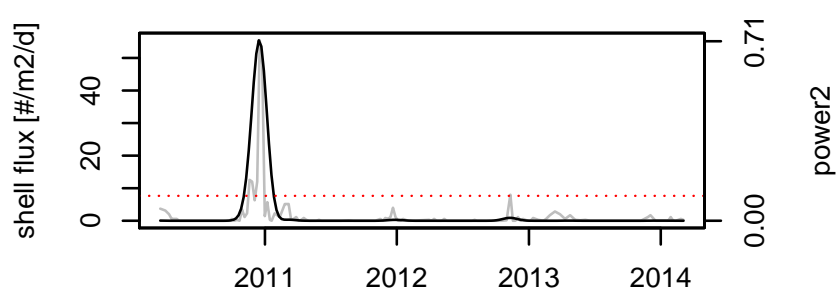

G_rubp425

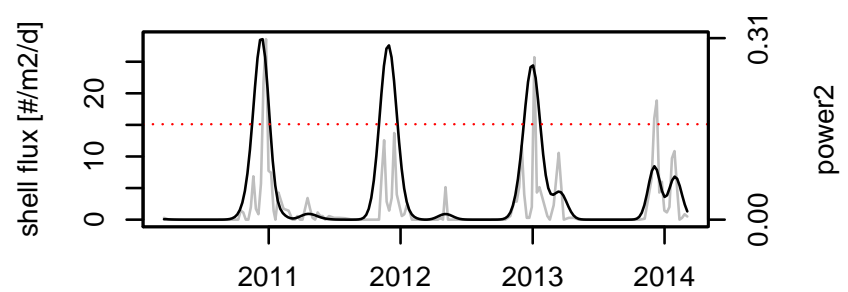

G_rubp212

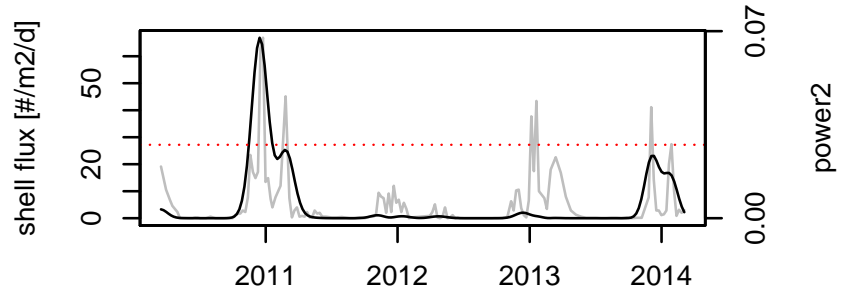


G_rubw425

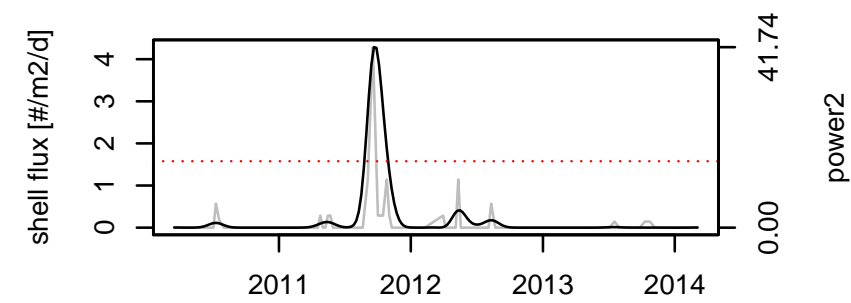

G_rubw212

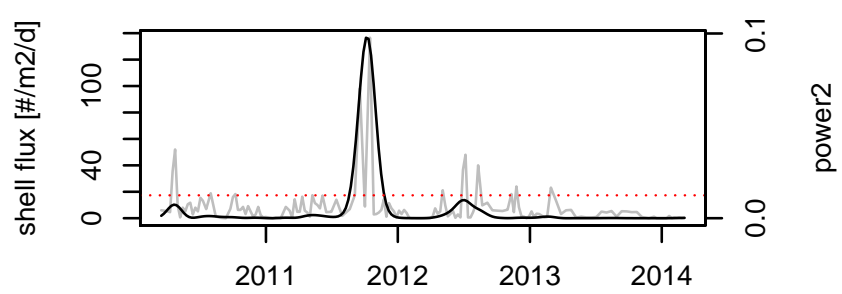

G_rubw300

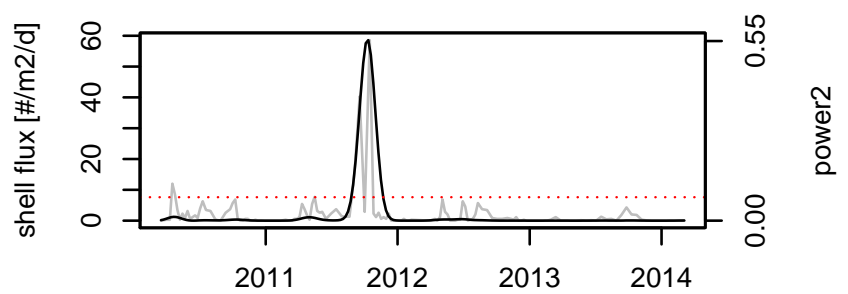

G_rubw150

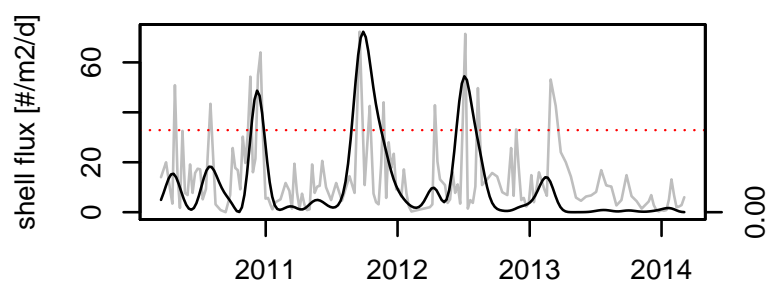


P_obl500

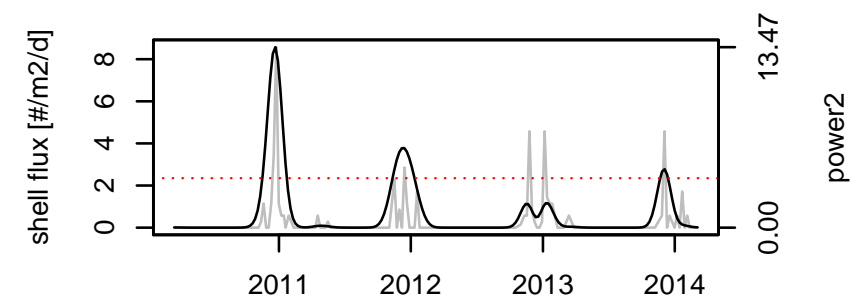

P_ob/300

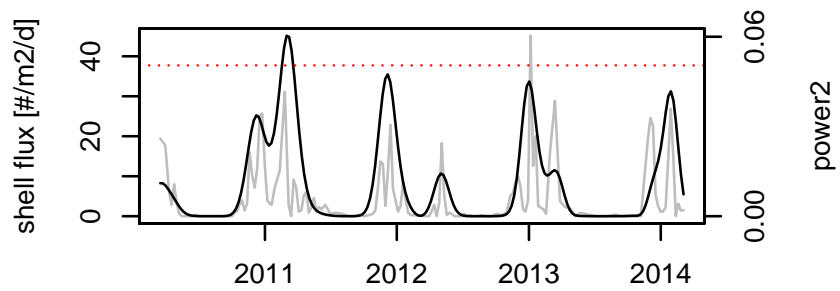

P_obl150

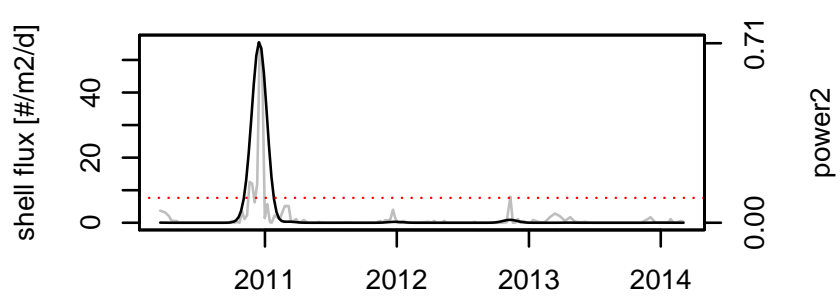

P_ob/425

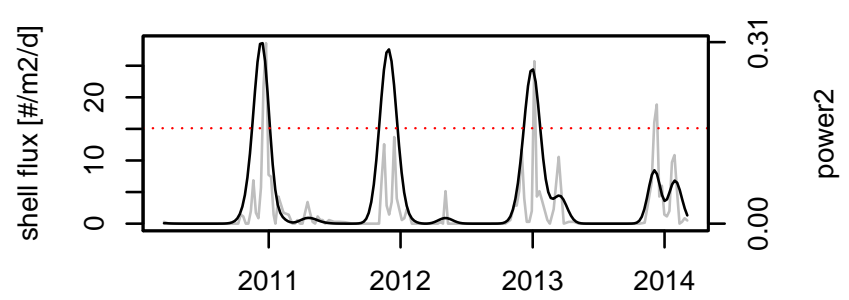

P_obl212

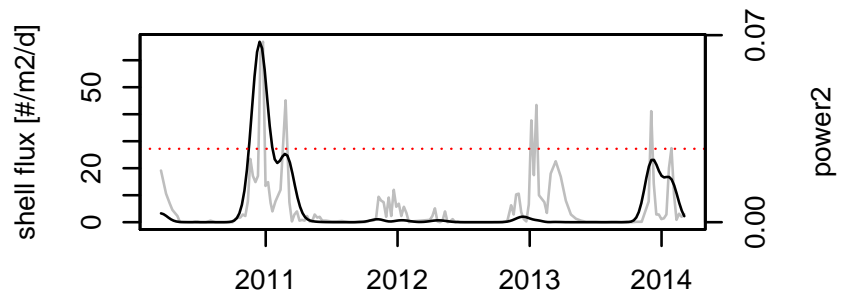



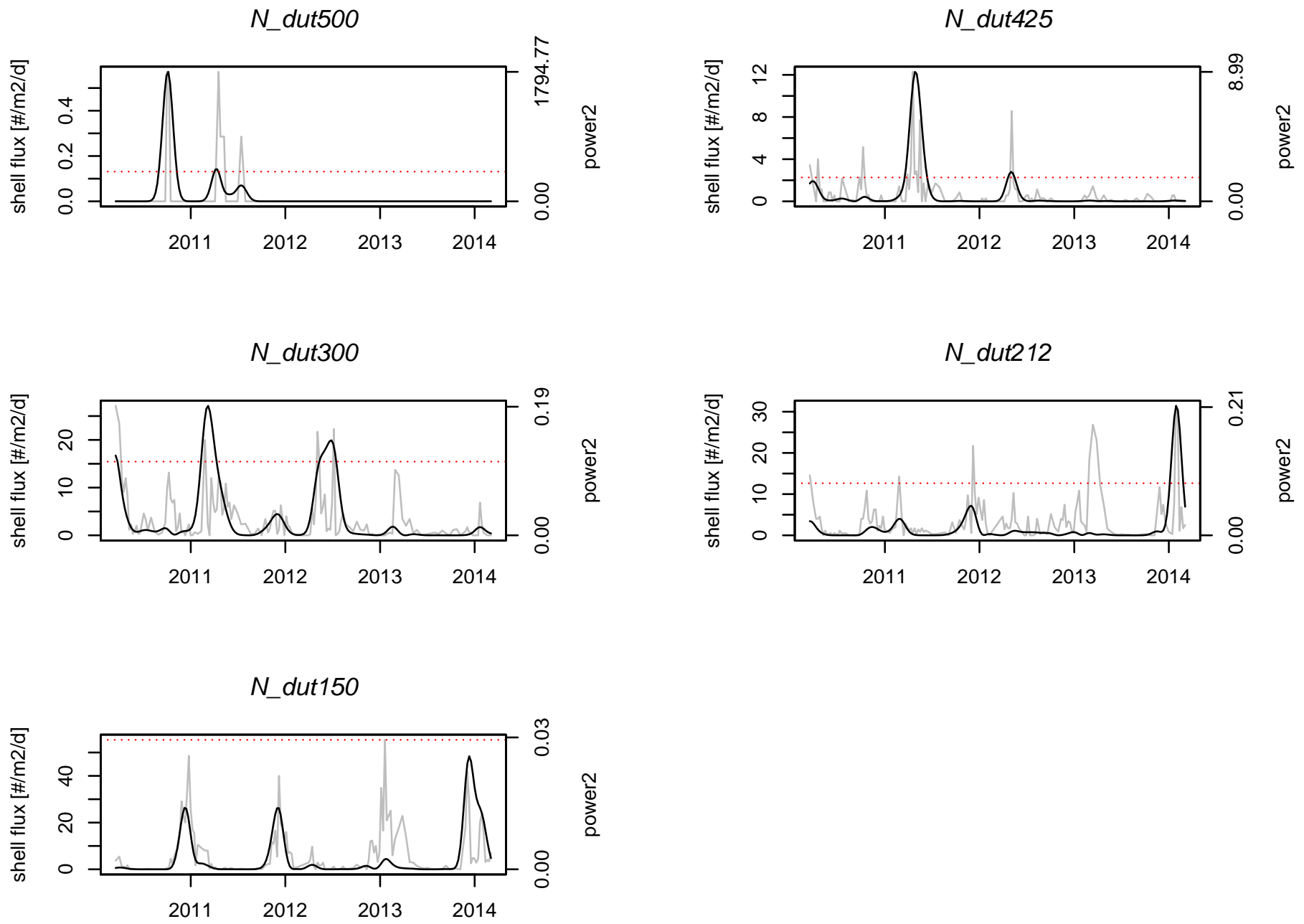
G_cal425

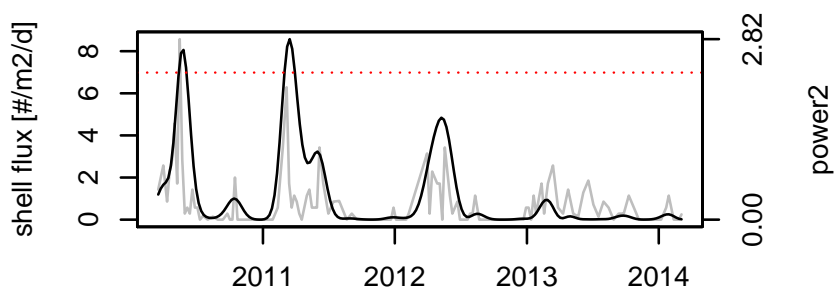

G_cal212

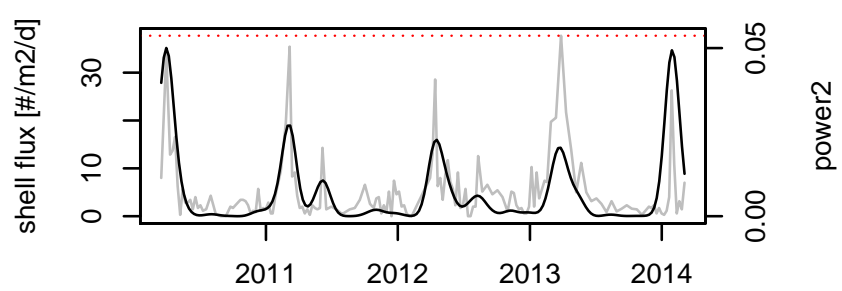

G_cal300

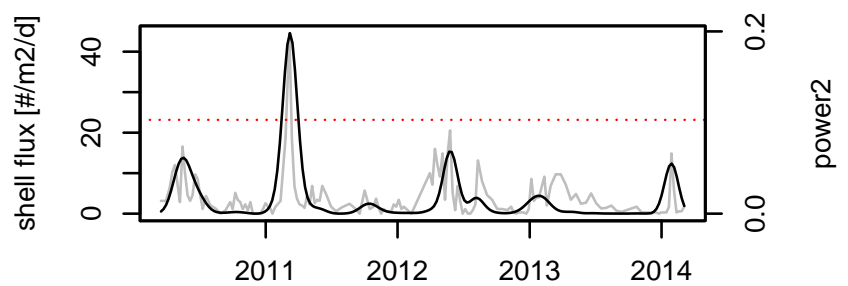

G_cal150

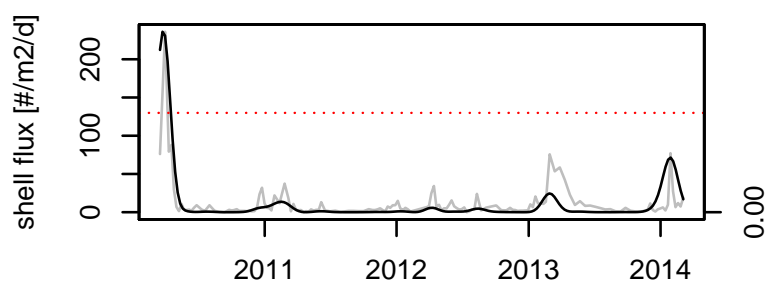



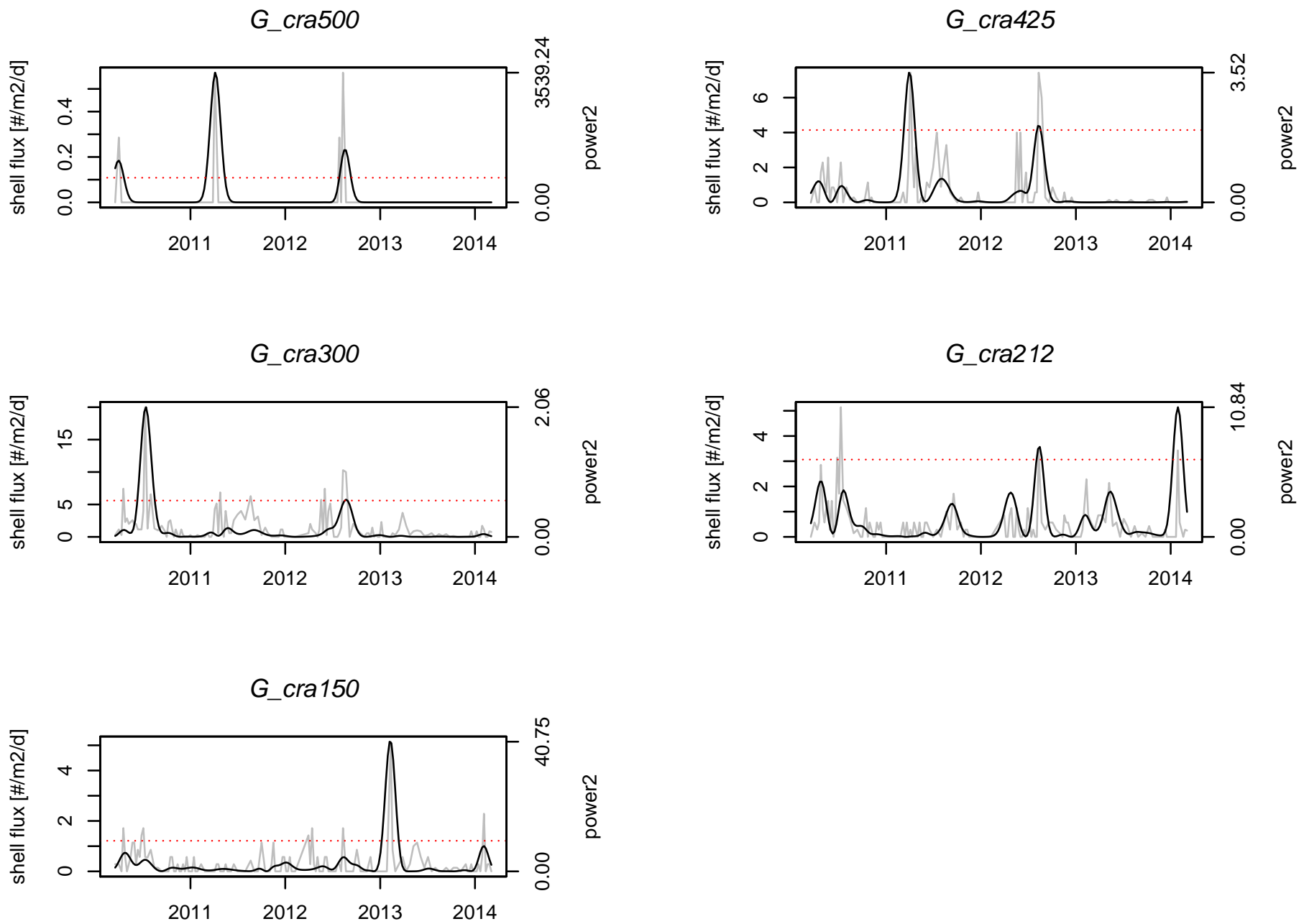

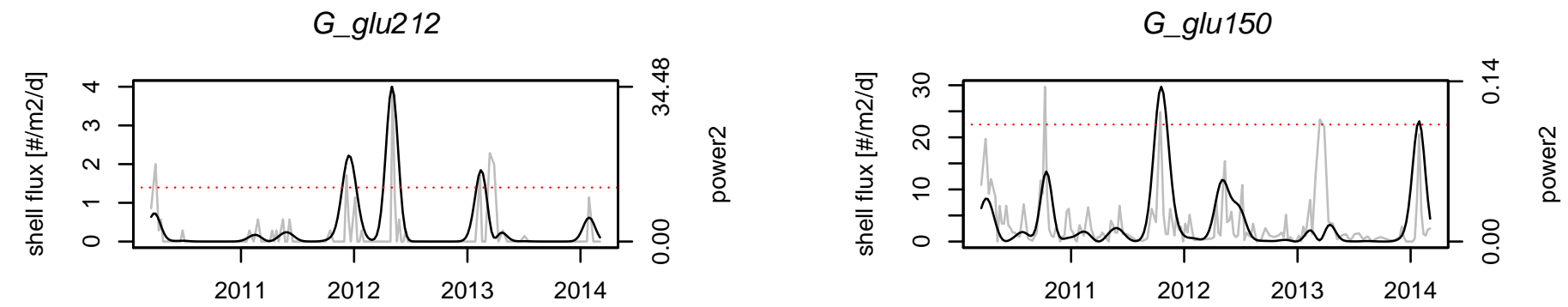


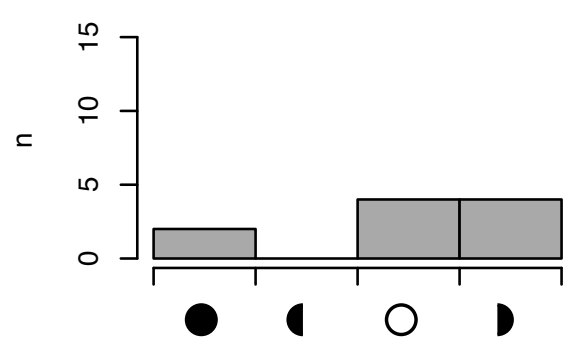

lunar phase

G_men300

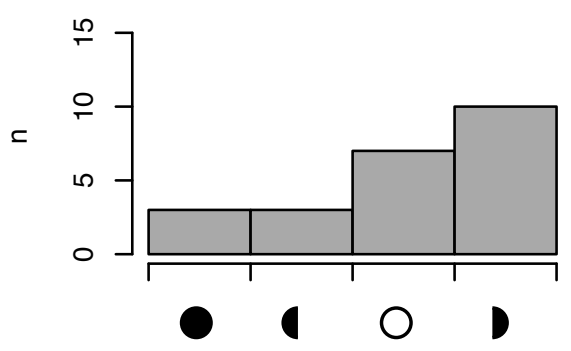

lunar phase

G_sip600

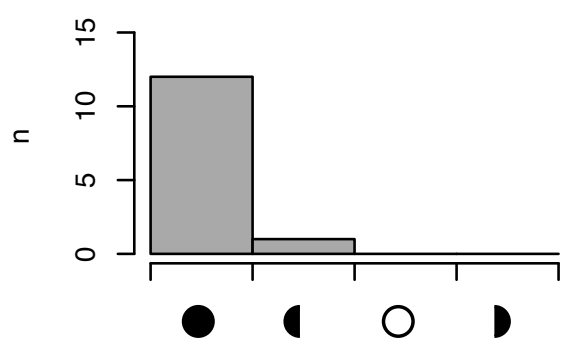

lunar phase

O_uni500

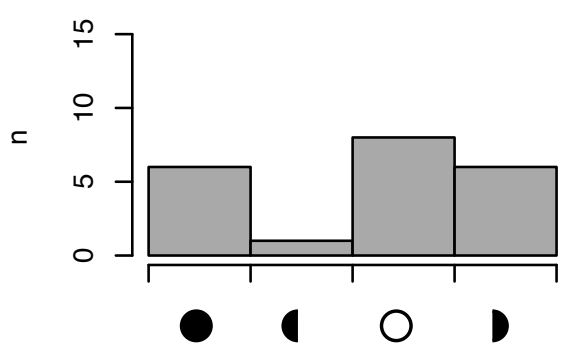

lunar phase

G_sac212

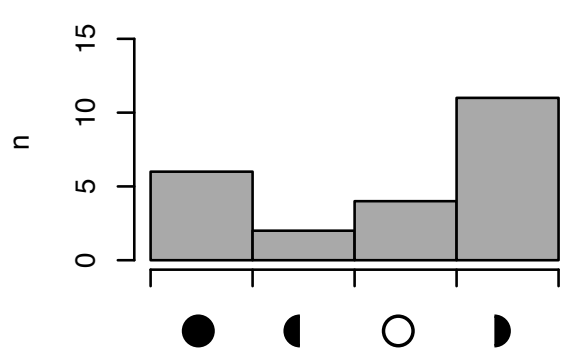

lunar phase

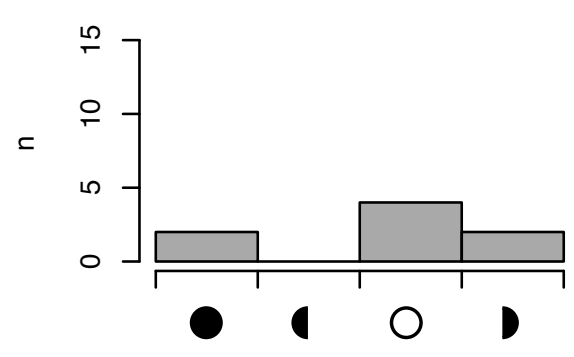

lunar phase

G_men212

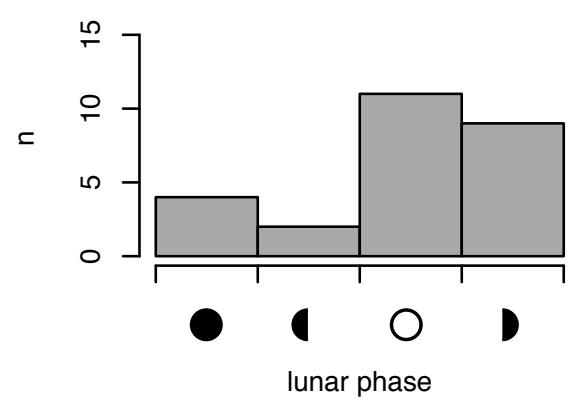

G_sip500

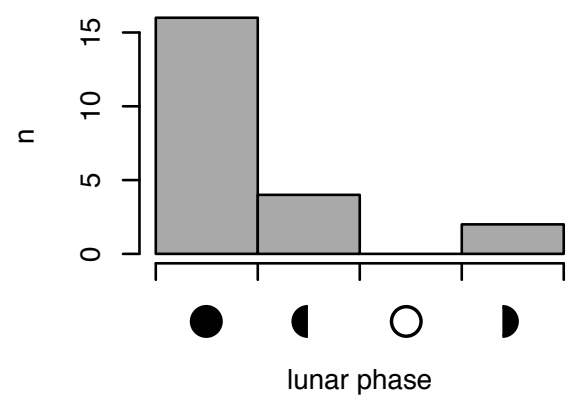

O_uni425

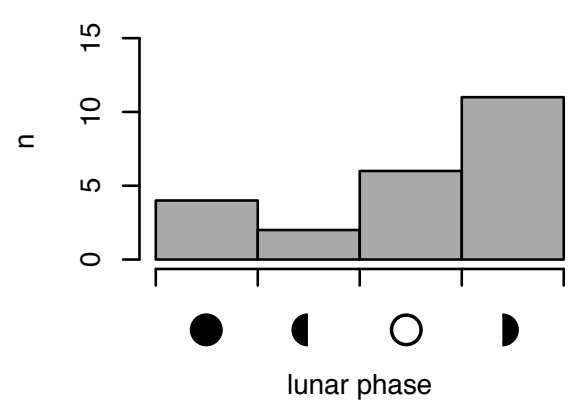

G_rubp425

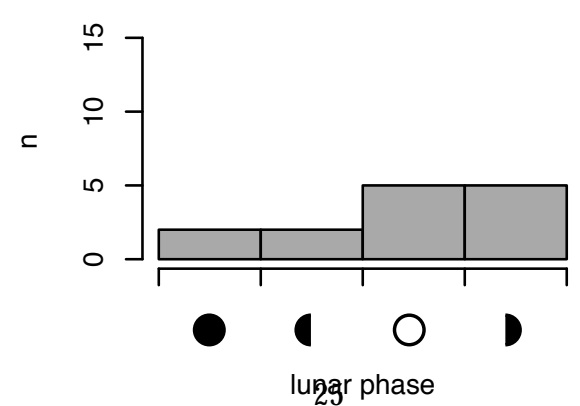

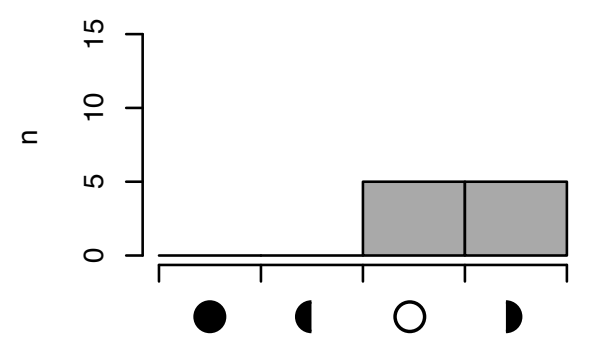

lunar phase

G_men150

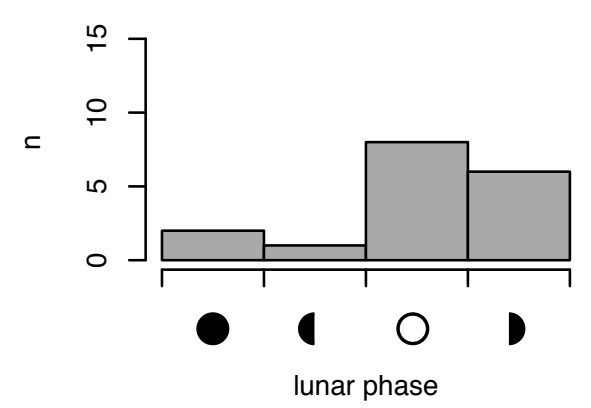

G_sip425

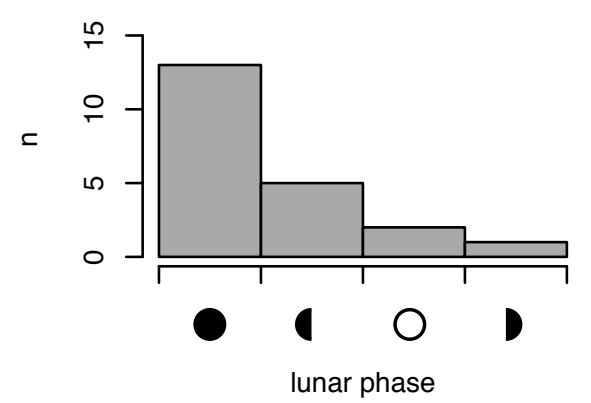

G_sac300

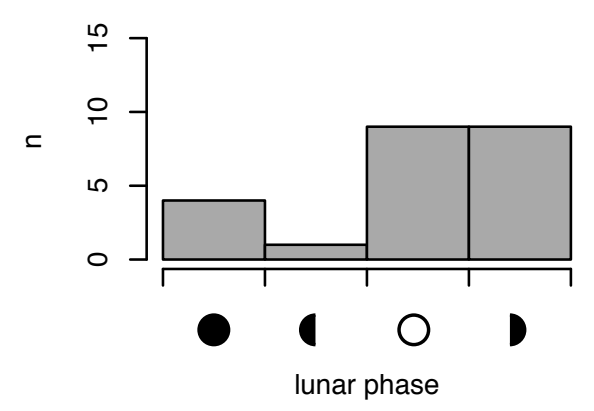

G_rubp300

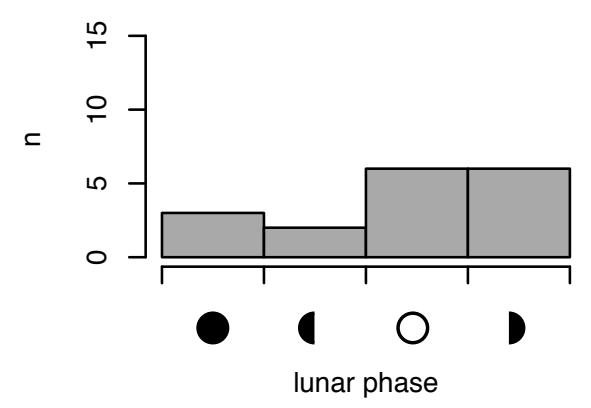




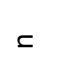

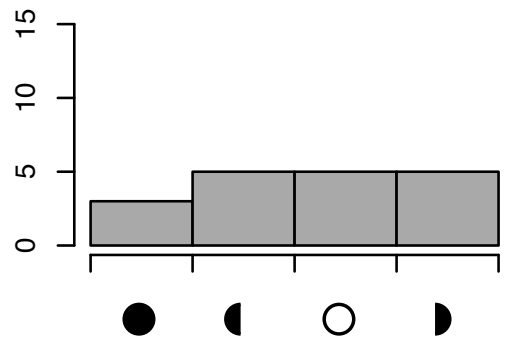

lunar phase

P_ob/300

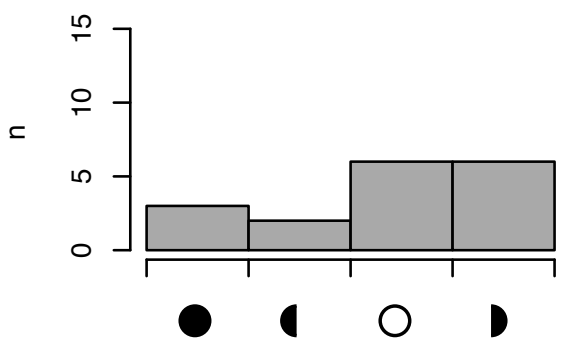

lunar phase

G_cal425

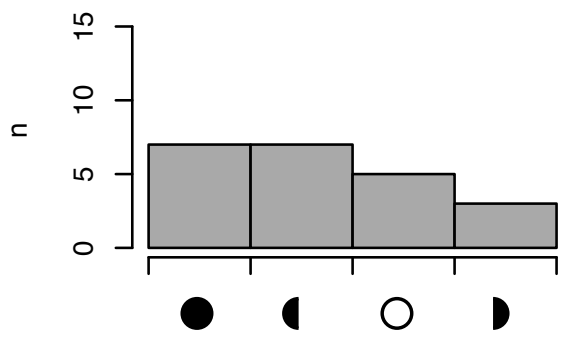

lunar phase

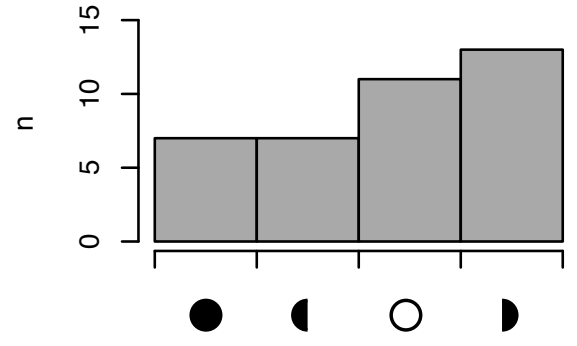

lunar phase

N_dut300

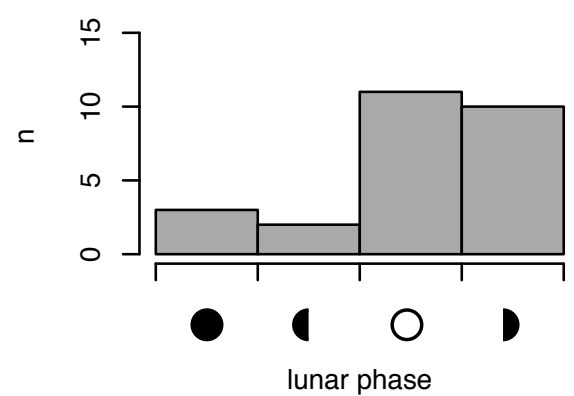

G_glu150

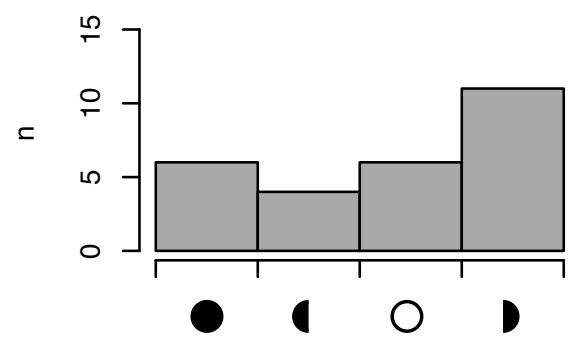

lunar phase

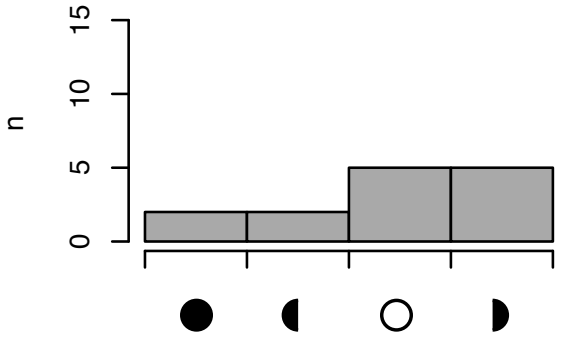

lunar phase

N_dut212

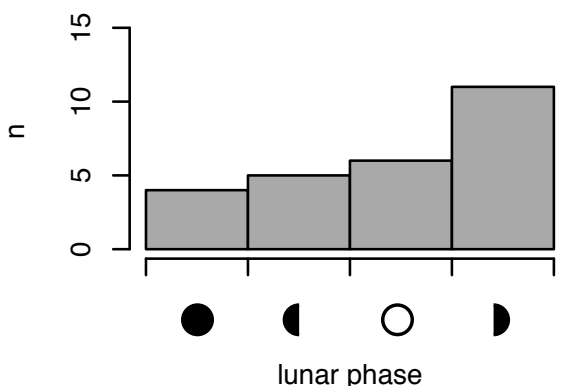

